\title{
ПСИХОЛОГИЧЕСКИЕ ФАКТОРЫ ВЕРОЯТНОСТНЫХ ЛИЧНОСТНЫХ РАССТРОЙСТВ
}

\author{
Казиева А.Т., Бибилова З.Л., Худалова М.З. \\ ФБГОУ ВО «Северо-Осетинский государственный университет \\ имени Коста Левановича Хетагурова», г. Владикавказ, \\ Российская Федерация
}

Вследствие распространения нарушений адаптащии и аутоидентификачии в современном обществе, а так же,противоречивой информации о факторах возникновения личностных расстройств, нас заинтересовал вопрос о связи данного расстройства с индивидуальнопсихологическими особенностями личности. Для изучения этой проблемы нами осуществлено исследование с привлечением 40 человек обоих полов и разного возраста, в котором применены методики для диагностики личностных черт и степени вероятностного расстройства личности. В результате была обнаружена коррелячионная связь между проявленияли вероятностного личностного расстройства и индивидуально-психологическими особенностями респондентов нашей выборки.

Ключевые слова: вероятностное личностное расстройство; индивидуально-психологические особенности; уровень психопатизации; пограничное расстройство; уровень нейротизма; эмоциональная устойчивость.

\section{PSICHOLOGICAL FACTORS OF PROBABILISTIC PERSONALITY DISORDER}

\author{
Kazieva A.T., Bibilova Z.L., Khudalova M.Z.
}

Noth Ossetia State University named offer Kosta Levanovich Khetagurov, Vladikavkas, Russian Federation

Owing to the spread of violations of adaptation and auto-identification in modern society as well as conflicting information about the factors 
of occurrence of personality disorders we were interested in question of the correlation individual psychological characteristics. We carried out a study involving 40 people of both sexes and different ages in which we applied methods to diagnose personality traits and the degree of probabilistic personality disorder to study this problem. A correlation was found between the manifestation of personality disorder and individual-psychological characteristics in our sample as a result.

Keywords: probabilistic personality disorder; individual-psychological characteristics; psychopathization rate; boderline disorder; neuroticismrate; emotional stability.

\section{Введение}

Практически невозможно найти голоса возражений в научном психологическом и психотерапевтическом сообществах против глубокого и серьезного изучения личностных расстройств. Актуальность темы велика. Научное и психотерапевтическое сообщества убеждены, что остро стоит необходимость развития современной теории и практики психологии и психотерапии личностных расстройств, в том числе через вопросы образования, внедрения практических подходов. В пользу роста интереса к проблеме говорит положительная динамика статистики обращения населения страны за профессиональной помощью в последние 2-3 года. Обзор литературы по данной теме дает нам возможность акцентировать на нескольких важных научных трудах. Среди которых работы ученых Института психотерапии и медицинской психологии им. Б.Д. Карвасарского (2016-2018 гг.). Ими изучались вопросы феноменологии, они обратили внимание на значительное количество терминов, отражающих феномены нарушения личности. Феноменология этих состояний различна, базируется на различных теоретических основаниях, требует различных подходов к психотерапевтической практике. Учеными института, Р.К. Назыровым [1], [2], И.С. Королевой, А.А. Климовым, Е.В. Шляхетко [3], В.Я. Сазоновым, И.С. Лысенко были сделаны шаги в понимании личностных аномалий. Также, ими были предприняты попытки понять природу механизмов личностных расстройств, в работах они зада- 
ются вопросом «не коренится ли механизм этих патологий в тканевых механизмах, в психофизиологии». Но все равно, по их мнению, тема явно не исчерпана. Современная наука в вопросе личностных аномалий опирается на подход Э.Крепелина [4], говорившего о существовании нескольких пространств психического: низший уровень - «нервная ткань», средний уровень - психические процессы и состояния, и высший уровень - процессы которые касаются самой личности, как системного социального ответа, что представляет собой самую высшую, экзопсихическую часть, эпифеномен [5], в понимании А.Ф. Лазурского [6], [7]. Мы в своей работе придерживаемся позиции В.М. Мясищева в определении личности: «Личность - это система, сформированных и реализуемых в обществе отношений человека к действительности, субъектом которых он является» [8], [9]. Также, мы исходим из подхода определения типа личности Дж. Олдхэма (John M. Oldham) и Луи Морриса (Lois B. Morris) (1994 г.) [10], которые основываясь на «Диагностическом и статистическом руководстве Американской психиатрической ассоциации» DSM-IV (и частично DSM-III-R) описывают их обычные, непатологические версии - категории нормального человеческого поведения. Их подход не направлен на диагностику болезни, а позволяет увидеть составные части личности. Термин «вероятностное личностное расстройство» весьма широко применим в известных кругах, и отражает пограничную степень личностного расстройства. Этим продиктован выбор методов данного исследования, целью которого является - исследование психологических факторов вероятностных личностных расстройств. Нами поставлены следующие задачи: определение типа личности и уровня психопатизации, диагностика индивидуальнопсихологических особенностей респондентов, математическая обработка результатов [11].

\section{Материалы и методы исследования}

Для изучения данной проблемы было проведено исследование, в котором приняли участие 40 человек. Возрастной диапазон респондентов - от 18 до 55 лет. Нами использовались следующие методи- 
ки: методика определения типа личности и вероятности личностных расстройств (Олдхэм-Моррис) [12], опросник «Уровень невротизации и психопатизации» (И.Б. Ласко и Б.И. Тонконогий) [13], пятифакторный личностный опросник (Р. МакКрае, П. Коста) [14].

\section{Результаты исследования}

В ходе исследования нами был выявлен низкий уровень психопатизации у $35 \%$ респондентов, $33 \%$ респондента попали в зону неопределенного результата (-5 до +5 по шкале психопатизации), патология по шкале психопатизации была диагностирована у $32 \%$ респондентов. Результаты по методике определения типа личности Олдхэма-Моррис, представленные в процентном соотношении, обнаружили преобладающие типы личности (см. рис. 1).

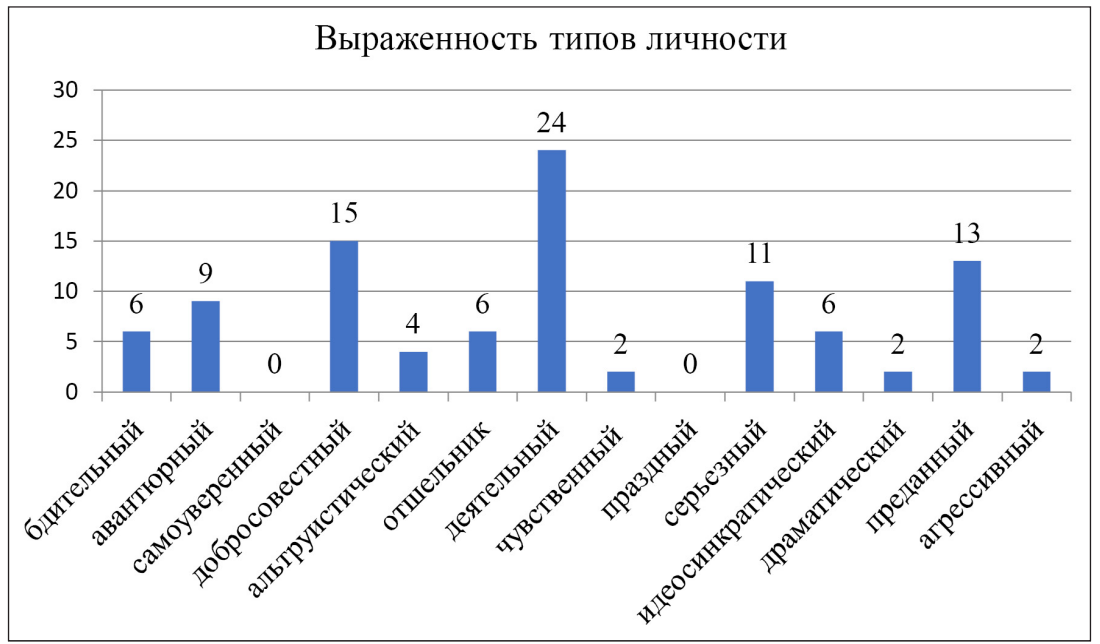

Рис. 1. Преобладающие типы личности по методике Олдхэма-Морриса

По каждому респонденту был составлен личный профиль, состоящий из идентичного набора типов. Но для удобства мы проклассифицировали их по ведущему типу. Итак, ведущими типами личности среди респондентов всей выборки являются: «деятельный - гиперактивный», «добросовестный - навязчиво-принуди- 
тельный», «преданный - зависимый», «серьезный - депрессивный», «авантюрный - антисоциальный». В сумме они составляют $72 \%$ из всего числа выборки.

Анализ полученных данных по пятифакторному личностному опроснику представлен на рис. 2.

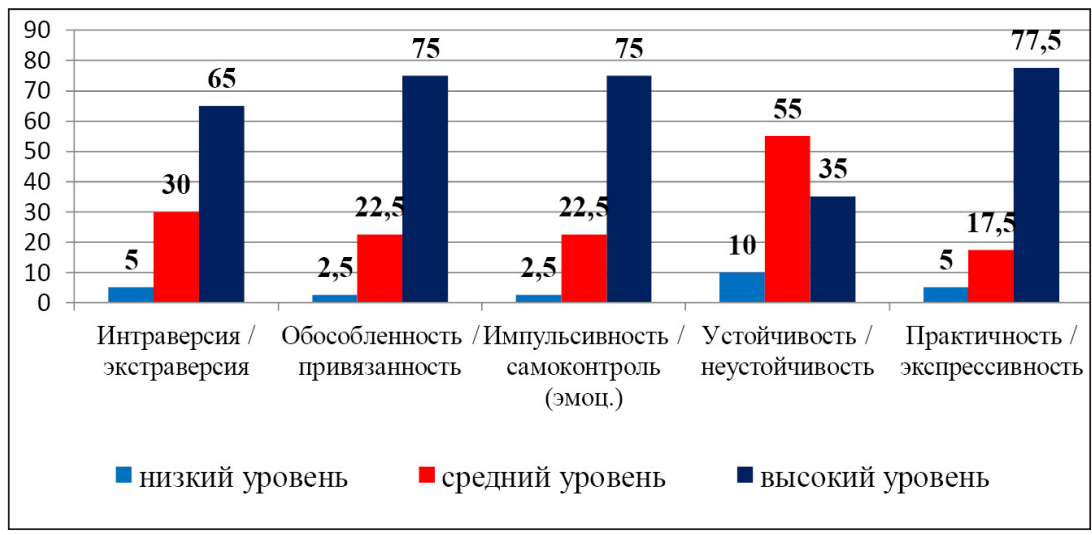

Рис. 2. Распределение респондентов по шкалам пятифакторного личностного опросника (в \%), $\mathrm{n}=40$

У большинства испытуемых по каждому фактору был выявлен высокий показатель. Общая характеристика выборки (по соотношению выраженности индивидуально-психологических особенностей): экстраверты, лица испытывающие потребность быть рядом с другими людьми, терпимо относятся к их недостаткам. Стараются избегать разногласий, не любят конкуренции, больше предпочитают сотрудничать с людьми, чем соперничать. Добросовестны, обязательны, аккуратны в делах, любят порядок и комфорт, Они придерживаются моральных принципов, не всегда могут позволить себе дать волю чувствам. Их поведение во многом обусловлено ситуацией. Они с тревогой ожидают неприятностей, в случае неудачи легко впадают в отчаяние и депрессию. Такие люди хуже работает в стрессовых ситуациях, в которых испытывают психологическое напряжение. У них, как правило, занижена самооценка, они обидчивы. Респонденты в целом склонны удовлетворять свое 
любопытство, проявляя интерес к различным сторонам жизни. Это эмоциональные, экспрессивные, с хорошо развитым эстетическим и художественным вкусом люди.

\section{Обсуждение}

Корреляционный анализ по Спирмену дает нам право сделать следующие выводы: чем выше у респондентов эмоциональная устойчивость, тем больше респондентам свойственны наблюдательность, спокойствие, беспристрастность и не сентиментальность ( $\rho=0,56$ при $p \leq 0,01)$ по типу личности «отшельник», а также с увеличением эмоциональной устойчивости респондентам больше будут свойственны реалистичное отношение к действительности, высокая приспособляемость к переменам обстоятельств, смене климата и другим неприятностям по типу личности «серьезный» $(\rho=0,46$ при $p \leq 0,01)$. Также эмоциональная устойчивость связна с такими личностными особенностями, как лояльность, сердечность, преданность, заботливость. По типу личности «преданный» $(\rho=0,60$ при $p \leq 0,01)$. Чем больше эмоциональной устойчивости тем меньше проявлений личностных расстройств по 4-му критерию: вредительство, наносимое самому себе $(\rho=-0,37$ при $p \leq 0,05)$ и меньше психопатизации ( $\rho=0,60$ при $p \leq 0,01)$. Чем выше у респондентов психопатизация, тем меныше им свойственны дружественные отношения, комфорт, довольство, воодушевление. По типу личности «чувствительный» $(\rho=0,38$ при $p \leq 0,01)$ Повышение экстраверсии сопровождается повышением лояльности, сердечности, преданности, заботливости. По типу личности «преданный» $(\rho=0,60$ при $\mathrm{p} \leq 0,01)$.

Эти достоверные результаты исследования представляются нам важными и могут быть использованы при практической работе клинического психолога, психотерапевта для повышения профессиональной эффективности.

\section{Заключение}

Данное исследование весьма актуально, нами были доказаны корреляционные связи между вероятностными личностными расстройствами и индивидуально-личностными особенностями. Среди 
которых: эмоциональная устойчивость / неустойчивость, экстраверсия / интроверсия, повышенный уровень психопатизации.

Информация о конфликте интересов. Авторы заявляют об отсутствии конфликта интересов.

Информация о спонсорстве. Исследование не имело спонсорской поддержки.

\section{Список литературы}

1. Назыров Р.К. Об оценке качества психотерапевтической помощи / Р.К. Назыров, Н.Д. Букреева // Вестник неврологии, психиатрии и нейрохирургии. 2012. № 2. С. 23-28.

2. Назыров Р. К. О развитии клинической психотерапии / Р.К. Назыров, В.В. Холявко // XV Съезд психиатров России, Москва, 9-12 ноября 2010 г.: материалы съезда. М.: ИД «Медпрактика-М», 2010. С. 316.

3. Шляхетко Е.В. Психодиагностика и психотерапия психосоматических эквивалентов стресса у бронхиальной астмой. М., 2001.

4. Овсянников С.А. // Крепелин Э. Введение в психиатрическую клинику. М., 2004, с. 482-490.

5. Савенко Ю.С. Эмиль Крепелин - это Аппиева дорога психиатрии... // НПЖ, 2001, 3, с. 5-6.

6. Леонтьев Д.А. Теория личности А.Ф. Лазурского: от наклонностей к отношениям // «Методология и история психологии». 2008. Т.3. № 4. С. 7-20.

7. Смирнов В.А. Психологические воззрения Александра Федоровича Лазурского. Дисс. к.псих.н. М., 1998.

8. Акименко М.А., Вассерман Л.И., Иовлев Б.В., Карпова Э.Б. От психоневрологии к медицинской психологии: научная система В.М. Бехтерева и В.Н. Мясищева. [Электронный ресурс] // Медицинская психология в России: электрон. науч. журн. 2011. N 4. URL: http://medpsy.ru

9. Вассерман, Л.И., Иовлев, Б.В., Карвасарский, Б.Д., Карпова, В.Н. Мясищев и медицинская психология (к 110-летию со дня рождения и 30-летию со дня смерти) // Журнал «Обозрение психиатрии и медицинской психологии», 2004, Т. 1, № 1. 
10. Олдхэм Дж., Моррис Л. Узнай себя. Автопортрет вашей личности. М.: Вече, 2007.

11. Наследов А.Д. Математические методы психологического исследования. Анализ и интерпретация данных. С.-Пб.: Речь, 2008.

12. Мамедова Л.В. Методы взаимодействия с людьми в зависимости от их типов личности, определенных по методике Олдхэма-Морриса // Современное педагогическое образование. 2019. № 5. С. 175-178.

13. Арзютова А.А. Индивидуально-психологические предпосылки невротизации личности // Поволжский педагогический вестник. 2014. № 2 (3). URL: https://cyberleninka.ru/article/n/individualno-psihologicheskiepredposylki-nevrotizatsii-lichnosti-1 (дата обращения: 04.09.2020).

14. Хромов А.Б. Пятифакторный опросник личности: Учебно-методическое пособие. Курган: Изд-во Курганского гос. университета, 2000. $23 \mathrm{c}$.

\section{References}

1. Nazyrov R.K. On the assessment of the quality of psychotherapeutic assistance / R.K. Nazyrov, N.D. Bukreeva // Bulletin of Neurology, Psychiatry and Neurosurgery. 2012. No. 2. P. 23-28. [Ob otsenke kachestva psikhoterapevticheskoy pomoshchi].

2. Nazyrov RK About the development of clinical psychotherapy [O razvitii klinicheskoy psikhoterapii] / RK. Nazyrov, V.V. Kholyavko // XV Congress of Russian Psychiatrists, Moscow, November 9-12, 2010: materials of the Congress. M.: ID "Medpraktika-M", 2010. S. 316.

3. Shlyakhetko E.V. Psychodiagnostics and psychotherapy of psychosomatic equivalents of stress in bronchial asthma. [Psikhodiagnostika i psikhoterapiya psikhosomaticheskikh ekvivalentov stressa u bronkhial'noy astmoy] M., 2001.

4. Ovsyannikov S.A. // Kraepelin E. Introduction to a psychiatric clinic [Krepelin E. Vvedeniye v psikhiatricheskuyu kliniku]. M., 2004, p. 482-490.

5. Savenko Yu.S. Emil Kraepelin is the Appian road of psychiatry ... [Emil' Krepelin - eto Appiyeva doroga psikhiatrii] // NPZh, 2001, 3, p. 5-6.

6. Leontiev D.A. Personality theory A.F. Lazursky: from inclinations to attitudes [Teoriya lichnosti A.F. Lazurskogo: ot naklonnostey k otnosheniyam] // Methodology and history of psychology. 2008. T.3. No. 4. P. 7-20. 
7. Smirnov V.A. Psychological views of Alexander Fedorovich Lazursky [Psikhologicheskiye vozzreniya Aleksandra Fedorovicha Lazurskogo]. Diss. PhD in Psychology. M., 1998.

8. Akimenko M.A., Wasserman L.I., Iovlev B.V., Karpova E.B. From neuropsychiatry to medical psychology: the scientific system of V.M. Bekhterev and V.N. Myasishchev [Ot psikhonevrologii k meditsinskoy psikhologii: nauchnaya sistema V.M. Bekhtereva i V.N. Myasishcheva]. [Electronic resource] // Medical psychology in Russia: electron. scientific. zhurn. 2011. N 4. URL: http://medpsy.ru

9. Wasserman L.I., Iovlev B.V., Karvasarsky B.D., Karpova V.N. Myasishchev and medical psychology (to the 110th anniversary of his birth and the 30th anniversary of his death) [Myasishchev i meditsinskaya psikhologiya (k 110-letiyu so dnya rozhdeniya i 30-letiyu so dnya smerti)] // Journal "Review of Psychiatry and Medical Psychology", 2004, Vol. 1, No. 1

10. Oldham J., Morris L. Know yourself. Self-portrait of your personality [Uznay sebya. Avtoportret vashey lichnosti]. M.: Veche, 2007.

11. Nasledov A.D. Mathematical methods of psychological research. Analysis and interpretation of the data [Matematicheskie metody psihologicheskogo issledovanija. Analiz i interpretacija dannyh] S.-Pb.: Rech', 2008 .

12. Mamedova L.V. Methods of interaction with people depending on their personality types, defined by the Oldham-Morris method [Metody vzaimodeystviya s lyud'mi v zavisimosti ot ikh tipov lichnosti, opredelennykh po metodike Oldkhema-Morrisa] // Modern pedagogical education. 2019. No. 5. P. $175-178$.

13. Arzyutova A.A. Individual psychological prerequisites for personality neurotization [Individual'no-psikhologicheskiye predposylki nevrotizatsii lichnosti] // Povolzhsky pedagogical bulletin. 2014. No. 2 (3). URL: https://cyberleninka.ru/article/n/individualno-psihologicheskie-predposylki-nevrotizatsii-lichnosti-1 (date of access: 04/09/2020).

14. Khromov A.B. Five-factor personality questionnaire: Study guide [Pyatifaktornyy oprosnik lichnosti: Uchebno-metodicheskoye posobiye]. Kurgan: Publishing house of the Kurgan state. University, 2000. 23 p. 